\title{
Analysis of Risk Factors for Extubation Failure in Subjects Submitted to Non-Emergency Elective Intracranial Surgery
}

\author{
Milena Carlos Vidotto PT PhD, Luciana Carrupt Machado Sogame PT PhD, \\ Mariana Rodrigues Gazzotti PT PhD, Mirto Nelson Prandini MD PhD, \\ and José Roberto Jardim MD
}

\begin{abstract}
BACKGROUND: Extubation failure is defined as the re-institution of respiratory support ranging from 24 to 72 hours following scheduled extubation and occurs in $2 \%$ to $25 \%$ of extubated patients. The aim of this study was to determine clinical and surgical risk factors that may predict extubation failure in patients submitted to non-emergency intracranial surgery. METHODS: This was a prospective observational cohort study. The study was carried out on 317 subjects submitted to nonemergency intracranial surgery for tumors, aneurysms, and arteriovenous malformation. Preoperative assessment was performed and subjects were followed up for the determination of extubation failure until either discharge from hospital or death. RESULTS: Twenty-six (8.2\%) of the 317 subjects experienced extubation failure following surgery. The following variables were considered for the multivariate analysis: level of consciousness at the time of extubation, duration of mechanical ventilation prior to extubation, sex and the use of intraoperative mannitol. The multivariate analysis determined that the most important variable for extubation failure was the level of consciousness at the time of extubation $(P=.001)$, followed by female sex, which also showed to be significant $(P=.006)$. CONCLUSIONS: Lower level of consciousness (GCS 8T-10T) and female sex were considered risk factors for extubation failure in subjects submitted to elective intracranial surgery. Key words: neurosurgery; craniotomy; ventilator weaning; intratracheal intubation; risk factors; postoperative period. [Respir Care 2012;57(12):2059-2066. (C) 2012 Daedalus Enterprises]
\end{abstract}

\section{Introduction}

Extubation failure is defined as the re-institution of respiratory support within $24-72$ hours following scheduled extubation, and occurs in $2-25 \%$ of extubated patients. The physiopathologic causes of extubation failure include

Drs Vidotto and Gazzotti are affiliated with the Department of Physiotherapy; Dr Prandini is affiliated with the Department of Neurosurgery; and Dr Jardim is affiliated with the Respiratory Division, Universidade Federal de São Paulo, São Paulo, Brazil. Dr Sogame is affiliated with the Department of Physiotherapy, Escola Superior de Ciências da Santa Casa de Misericórdia de Vitória (EMESCAM), Santa Luíza Vitoria, Espírito Santo, Brazil.

The authors have disclosed no conflicts of interest.

Correspondence: José R Jardim MD, Disciplina de Pneumologia, Universidade Federal de São Paulo, Rua Botucatu, 740-3 Andar 04023062, São Paulo, Brazil. E-mail: joserjardim@yahoo.com.br.

DOI: $10.4187 /$ respcare.01039 an imbalance between the respiratory muscles and respiratory work, obstructions of the upper airway, hypersecretion, ineffective cough, encephalopathy, cardiac dysfunction, and atelectasis. ${ }^{1-4}$ Extubation failure raises the incidence of mortality, pneumonia, number of days in the ICU and hospital, time spent on mechanical ventilation (MV), hospital costs, and the need for tracheostomy. ${ }^{2,5,6}$

A number of studies have assessed the relationship between pre/intraoperative characteristics and extubation outcome in the postoperative period among patients undergoing general surgery. ${ }^{7-9}$ These studies suggest that risk factors for extubation failure may be inherent to both patient and surgery. Risk factors specific to patients can be divided into different states: general status of the patient (age, APACHE II, diabetes mellitus, cancer, alcohol use), lung status (smoking habits, COPD, nutritional state), neurological status (altered level of consciousness), cardiac status (acute myocardial infarction), and renal status (renal insufficiency, blood transfusion). Surgical risk factors include the location of the incision in relation to the dia- 
phragm, emergency surgery, and type of anesthesia (general or spinal). ${ }^{10-12}$ Extubation is particularly controversial in neurological patients. The timing of extubation in the neurologically impaired patient is a situation that requires an attempt to balance risk and benefit, as both prolonged intubation and extubation failure have been associated with long-term consequences. ${ }^{6,13-16}$

Patients undergoing neurosurgery are predisposed to a variety of complications related to MV. A number of prospective and retrospective studies have demonstrated an increased incidence of reintubation, pneumonia, and prolonged MV among such patients., ${ }^{4,6,13-17}$ Weaning guidelines based upon traditional predictive indexes prove limited when used on patients undergoing neurosurgery..$^{14,16,18}$

The aim of the present study was to determine clinical and surgical risk factors that may predict extubation failure in patients submitted to non-emergency intracranial surgery.

\section{Methods}

\section{Study Population}

A prospective observational cohort study was carried out over 48 consecutive months. Patients in the postoperative period of non-emergency intracranial surgery for tumors, aneurysms, arteriovenous malformations, intracranial hematomas, and abscess were admitted to the neurosurgery ICU and followed up until discharge or death. In this study only the data of the first extubation attempt was included, and all subjects signed an informed consent. A total of 434 patients in the preoperative period were assessed, 317 of whom were included. Among the 117 patients excluded, 21 died prior to weaning from MV; 11 underwent tracheostomy prior to weaning; 33 did not undergo the initially proposed surgery; 15 had the surgery cancelled; 5 required orotracheal intubation prior to surgery; 28 were referred to a different ICU in the postoperative period; and 4 had incomplete data regarding the surgery. This study was approved by the research and ethics committee of the university.

\section{Data Collection}

Clinical evaluations and physical examinations were performed by the same healthcare team for all subjects. The following preoperative variables were assessed on the day prior to surgery: sex, age, respiratory symptoms, previous pneumopathy, smoking habits, associated clinical diseases, previous craniotomy, and level of consciousness. Subjects were followed up on a daily basis from the immediate postoperative period until either discharge or subject death.

Subjects with orotracheal intubation were referred directly from the operating room to the neurosurgery ICU,

\section{QUICK LOOK}

\section{Current knowledge}

Extubation failure is defined as the re-institution of ventilatory support within 24-72 hours following scheduled extubation, and occurs in 2-25\% of cases. Extubation failure raises the incidence of mortality, pneumonia, number of days in the ICU and hospital, time spent on mechanical ventilation, hospital costs, and tracheostomy.

\section{What this paper contributes to our knowledge}

A lower level of consciousness, Glasgow coma score of 8-10 (intubated), and female sex are risk factors for extubation failure following intracranial surgery. Early respiratory intervention in these subjects may be warranted to prevent re-intubation.

where they were submitted to respiratory support using either the Bear 1000 (Allied Health Care Product, St Louis, Missouri), the Monterey (Takaoka, Brazil), or the Bird 8400 STI PC Vaps (Bird Products, St Paul, Minnesota) ventilators. Subjects were ventilated according to the following parameters: synchronized intermittent mandatory ventilation (volume control) modality, associated to pressure support (SIMV+PS); tidal volume of $6-8 \mathrm{~mL} / \mathrm{kg}$, with plateau pressure of $35 \mathrm{~cm} \mathrm{H}_{2} \mathrm{O}$ and peak pressure of $40 \mathrm{~cm} \mathrm{H}_{2} \mathrm{O}$ as upper limits of pressure; PEEP of $5 \mathrm{~cm} \mathrm{H}_{2} \mathrm{O}$; flow of $50 \mathrm{~L} / \mathrm{min} ; \mathrm{F}_{\mathrm{IO}_{2}}$ of 0.4 or another fraction that could maintain $\mathrm{S}_{\mathrm{pO}_{2}}$ over $93 \%$; respiratory rate sufficient to maintain adequate alveolar ventilation; sufficient pressure support to maintain tidal volume between $6 \mathrm{~mL} / \mathrm{kg}$ and $8 \mathrm{~mL} / \mathrm{kg}$.

The postoperative assessment included type, location, and duration of surgery, drugs used during surgical procedure, duration of MV, level of consciousness at the time of extubation, postoperative pulmonary complications, and stay in the ICU.

Subjects were divided into 3 groups, according to the type of intracranial surgery performed: resection of expansive lesions, including tumors, abscesses, and brain hematomas; aneurysm clipping, including bypass, trapping, and wrapping surgery; correction of arteriovenous malformation, including dural fistula and Moyamoya disease. Surgery location was divided into supratentorial and infratentorial, depending on the region affected. Extubation time was categorized into 3 groups, according to the time on MV since the beginning of surgery: $\leq 24$ hours; $>24$ hours and $<48$ hours; and $>48$ hours.

Extubation of subjects with under 24 hours MV was performed in either the operating room or the neurosurgery ICU. Due to the short period of time on MV, these subjects did not need to be weaned and were extubated on 
the following criteria: absence of sedatives; stable hemodynamics, without the need for vasoactive drugs; $\mathrm{S}_{\mathrm{pO}_{2}}$ $>95 \%$, with $\mathrm{F}_{\mathrm{IO}_{2}}<0.4$ and $5 \mathrm{~cm} \mathrm{H}_{2} \mathrm{O}$ of PEEP; Glasgow coma score $(\mathrm{GCS}) \geq 8$; presence of respiratory drive; arterial blood gases within normal parameters; and concordance from neurosurgeon in charge. The neurosurgical team who had performed the surgery were always those who decided when it was feasible to commence the withdrawal of sedation.

Subjects extubated after over 24 hours of MV underwent the weaning process, which was initiated when they showed: absence of sedatives and vasoactive drugs; hemodynamic stability; adequate respiratory drive, with the absence of apnea or tachypnea (respiratory rate $<35$ breaths/min); no immediate upcoming surgery scheduled; laboratory exams within normality range; arterial blood gases within normal ranges $(\mathrm{pH}$ between 7.35 and 7.45; $\mathrm{P}_{\mathrm{aCO}_{2}}$ between $30 \mathrm{~mm} \mathrm{Hg}$ and $40 \mathrm{~mm} \mathrm{Hg}$ ); $\mathrm{P}_{\mathrm{aO}_{2}}$ $>60 \mathrm{~mm} \mathrm{Hg}$, with $\mathrm{F}_{\mathrm{IO}_{2}} \leq 0.4$ and PEEP $\leq 5 \mathrm{~cm} \mathrm{H} \mathrm{H}_{2} \mathrm{O}$; reversion of reason for postoperative $\mathrm{MV} ; \mathrm{GCS} \geq 8$; and agreement by the neurosurgeon in charge.

\section{Weaning Process}

Subjects who fulfilled the weaning criteria were submitted to a spontaneous breathing trial (SBT). The SBT consisted of 30-120-min trials of spontaneous breathing performed on a T-tube or pressure support of $\leq 8 \mathrm{~cm} \mathrm{H}_{2} \mathrm{O}$ and PEEP level $\leq 5 \mathrm{~cm} \mathrm{H}_{2} \mathrm{O}$. All subjects ultimately passed an SBT and were extubated. The following criteria were used to define failure to tolerate the SBT: oxygen saturation $<90 \%$; respiratory rate of $>35$ breaths/min for $>10 \mathrm{~min}$; a decrease or increase in the systolic blood pressure of $>20 \%$; signs of increased breathing work for $>15 \mathrm{~min}$; and diaphoresis or agitation. The SBT was terminated and MV reinstituted at the original settings if 2 of the set predictors for poor tolerance were identified.

\section{Extubation Failure}

Extubation failure was considered when subjects required reintubation within 48 hours. The decision to reintubate was based on clinical deterioration, as evidenced by at least one of the following criteria: decreased mental status; altered arterial $\mathrm{pH}$ or $\mathrm{P}_{\mathrm{aCO}}$; decrease in oxygen saturation to $<90 \%$ despite $\mathrm{F}_{\mathrm{IO}_{2}}>0.5$; and increased signs of respiratory distress (tachypnea, use of accessory respiratory muscles, thoracoabdominal paradox).

The assessment of level of consciousness was based on a modified GCS. As the subjects were under MV and orotracheal intubation, the verbal response that would normally score a 5 scored only 1 , associated with the letter $\mathrm{T}$, indicating the need for an artificial airway and the inability to give a verbal response. We calculated the best motor response and eye opening, and scored $1 \mathrm{~T}$ to verbal response. Level of consciousness was characterized as normal for subjects with GCS of $11 \mathrm{~T}$ and altered with scores of $8 \mathrm{~T}$ to $10 \mathrm{~T} .{ }^{14}$

The following postoperative pulmonary complications were used in the present study ${ }^{19}$ :

- Acute respiratory infection, characterized by pneumonia and purulent tracheobronchitis. Pneumonia diagnosis was established by the presence of lung infiltration on the thorax radiograph, associated with at least 2 of the following signs: purulent tracheobronchial secretion, body temperature over $38.3^{\circ} \mathrm{C}$, and a $25 \%$ increase in the basal number of circulating leukocytes. Purulent tracheobronchitis was diagnosed when there was an increase in volume, change in color, or purulence of the tracheobronchial secretions associated with a normal thorax radiograph.

- Atelectasis: when the appearance of acute respiratory symptoms were associated with radiological imaging.

- Bronchospasm: wheezing in the lung associated with the development of acute respiratory symptoms and the need for bronchodilatation therapy.

\section{Statistical Methods}

The categorical variables are summarized in absolute and relative (percentage) frequencies. Numerical variables are expressed in mean and standard deviation. Only the stay in the ICU was expressed as median and interquartile variation $(\mathrm{Q} 1-\mathrm{Q} 3)$.

In the univariate analysis, either the chi-square test or the Fisher exact test was used to determine associations between the categorical variables and the outcome. The influence of the numerical values was analyzed by means of comparison of averages, using the Student $t$ test for independent samples. Only the stay in the ICU was assessed using the Mann-Whitney test for non-parametric data, as there was no normal distribution for this variable.

A logistic regression model was used to assess the simultaneous influence of risk factors on the outcome. Variables with descriptive levels ( $P$ values) lower than .15 in the univariate analysis were included in the multivariate model. All interaction effects between variables were analyzed. A statistical software program (SPSS 13.0, SPSS, Chicago, Illinois) was employed.

\section{Results}

From the 317 subjects included in this study, 26 (8.2\%) experienced extubation failure. Mean MV time prior to extubation was $26 \pm 55$ hours. A total of 150 subjects (47.3\%) were extubated in the operating room; 105 (33.2\%) 
Table 1. Distribution of 317 Patients Submitted to Intracranial Surgery, According to Demographic Characteristics

\begin{tabular}{lc}
\hline \hline Age, mean \pm SD y & $46 \pm 14$ \\
Male, no. (\%) & $138(44)$ \\
Respiratory symptoms, no. (\%) & $31(13.1)$ \\
Smoking status, no. (\%) & \\
Never & $151(48)$ \\
Stopped & $68(21)$ \\
$\quad$ Pack years, mean \pm SD & $22 \pm 18$ \\
Current smoker, no. (\%) & $98(31)$ \\
$\quad$ Pack years, mean \pm SD & $28 \pm 19$ \\
Pulmonary Disease, no. (\%) & $28(9)$ \\
Asthma & 7 \\
Neoplasm & 9 \\
Emphysema & 7 \\
Bronchitis & 5 \\
Clinical Disease, no. (\%) & $90(28)$ \\
Hypertension & 86 \\
Diabetes mellitus & 13 \\
Cardiac arrhythmia & 6 \\
Heart diseases & 4 \\
Stroke & 2 \\
Low level of consciousness in preoperative period, & $29(9)$ \\
no. (\%) & \\
\hline
\end{tabular}

were extubated before completing 24 hours of MV, and 62 (19.5\%) were extubated after 24 hours of mechanical extubation, 31 of whom $(9.8 \%)$ remained on MV for over 48 hours. Table 1 displays the characteristics of the 317 subjects included in the study. Table 2 displays the clinical and surgical variables regarding extubation failure.

We found no difference in the incidence of extubation failure with regard to the types of drugs used during the anesthesia procedure $(P>.05)$. Mannitol was used to reduce cerebral volume during surgery, and was the only drug used during anesthesia that showed a descriptive level lower than 0.15 in the univariate analysis $(P=.10)$ and also the only drug included in the multivariate model.

The following variables were considered for the multivariate analysis: level of consciousness at the time of extubation, duration of MV prior to extubation, sex, and the use of intraoperative mannitol. Interactions between variables were investigated, and an association between level of consciousness and duration of MV was found $(P=.001)$. Therefore, the variable duration of MV prior to extubation was excluded from the multivariate logistic regression model. The most important variable for extubation failure was the level of consciousness at the time of extubation $(P=.001)$, followed by female sex, which also proved to be significant $(P=.006)$ (Table 3$)$. The differences between the levels of consciousness, using a modified GCS, are described in Table 4.

A total of 31 subjects were ventilated for over 48 hours $(\mathrm{MV}>48 \mathrm{~h}): 42 \%$ females, with a mean age of
$45 \pm 17$ years, which was no different from the age of the 317 subjects that comprised the total group ( $46 \pm 14 \mathrm{y}$ ) in the study. Among the 31 subjects with MV $>48$ hours, 8 $(25 \%)$ presented extubation failure: despite the fact that the mean MV time prior to extubation was greater in those subjects who had failed extubation, it was not different from the group that succeeded extubation $(173,7 \pm 114 \mathrm{~h}$ vs $148.6 \pm 112.4 \mathrm{~h}$, respectively, $P=.60$ ). Seven of the 31 subjects remained in MV $>7$ days, and 3 of them (43\%) failed extubation.

Timing of extubation failure was analyzed among the 26 subjects who failed extubation within 48 hours, and it was divided in 4 groups: 5 subjects failed within 12 hours, 7 subjects failed between 12-24 hours, 9 subjects failed between 24-36 hours, and 5 subjects failed between $36-$ 48 hours. Only 2 subjects failed extubation after 48 hours within the next 72 hours, the cause of reintubation in both subjects being a decreased level of consciousness.

Out of 26 subjects who failed, only 4 received noninvasive ventilation (NIV) after extubation, due to signs of respiratory distress without altered level of consciousness. Among the subjects with successful extubation, only 3 received NIV, at most for one hour, due to tachypnea and signs of respiratory distress after extubation. The use of NIV in subjects with altered level of consciousness was avoided; using NIV in subjects with decreased level of consciousness could increase the risk of bronchoaspiration and associated pneumonia. As most subjects who failed extubation had altered level of consciousness, NIV was not routinely used.

The incidence of pulmonary complications, mortality, reoperation, and hospital stay in the postoperative period according to the occurrence of extubation failure is shown in Table 5.

\section{Discussion}

We observed in this study an $8.2 \%$ incidence of extubation failure in subjects submitted to non-emergency intracranial surgery. Altered level of consciousness (GCS $8 \mathrm{~T}-10 \mathrm{~T})$ at the time of extubation and female sex were found to be important risk factors for extubation failure.

This incidence is compatible with that described in the MV weaning guidelines, which report a reintubation rate ranging from $5 \%$ to $15 \%$ in a population including clinical and surgical patients. ${ }^{3}$ The incidence found in our study was lower, however, than the $16 \%$ incidence of extubation failure observed by Namen et al for neurosurgery patients, although these authors included in their study elective, emergency, cranioencephalic traumatism, and spine surgeries. ${ }^{16}$

Another study found a higher incidence of extubation failure (35.7\%), but in a mainly non-surgical neurological population including patients with ischemic vascular ac- 
Risk Factors for Extubation Failure After Intracranial Surgery

Table 2. Univariate Analysis of Clinical and Surgical Variables Regarding the Occurrence of Extubation Failure

\begin{tabular}{|c|c|c|c|}
\hline & $\begin{array}{c}\text { Success } \\
(n=291)\end{array}$ & $\begin{array}{c}\begin{array}{c}\text { Failure } \\
(n=26)\end{array} \\
\end{array}$ & $P$ \\
\hline Female & $160(55)$ & $19(73)$ & .08 \\
\hline Male & $131(45)$ & $7(27)$ & \\
\hline Age, mean \pm SD y & $46 \pm 14.2$ & $49 \pm 15.2$ & .38 \\
\hline Altered preoperative consciousness & $27(9)$ & $2(7)$ & $>.99$ \\
\hline Previous craniotomy & $52(18)$ & $5(19)$ & .79 \\
\hline Respiratory symptoms & $35(12)$ & $3(11)$ & $>.99$ \\
\hline Previous pneumopathy & $27(9)$ & $1(4)$ & .71 \\
\hline Smoker & $92(31)$ & $6(23)$ & .61 \\
\hline Ex-smoker & $61(20)$ & $7(27)$ & \\
\hline Co-morbidities & $83(28)$ & $7(27)$ & .86 \\
\hline Diagnosis & & & .74 \\
\hline Tumorous lesion & $182(62)$ & $15(58)$ & \\
\hline Aneurysm & $92(32)$ & $10(38)$ & \\
\hline Arteriovenous malformation & $17(6)$ & $1(4)$ & \\
\hline Location of surgery & & & .78 \\
\hline Supratentorial & $243(84)$ & $21(81)$ & \\
\hline Infratentorial & $48(16)$ & $5(19)$ & \\
\hline Altered consciousness at extubation & $30(10)$ & $11(42)$ & $<.001$ \\
\hline Duration of surgery, mean \pm SD min & $303 \pm 83.5$ & $291 \pm 109.3$ & .48 \\
\hline Duration of Ventilation & & & .004 \\
\hline$\leq 24 \mathrm{~h}(n=255)$ & $239(94)$ & $16(6)$ & \\
\hline $24-48 \mathrm{~h}(n=31)$ & $29(94)$ & $2(6)$ & \\
\hline$>48 \mathrm{~h}(n=31)$ & $23(74)$ & $8(25)$ & \\
\hline
\end{tabular}

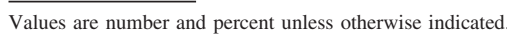

Table 3. Multivariate Analysis of Risk Factors for Extubation Failure in the Postoperative Period of Elective Intracranial Surgery

\begin{tabular}{lccc}
\hline \hline & $\begin{array}{l}\text { Odds } \\
\text { Ratio }\end{array}$ & $95 \%$ CI & $P$ \\
\hline Altered consciousness at extubation & 10.3 & $3.87-27.53$ & .001 \\
Female sex & 8.5 & $1.87-38.64$ & .006 \\
Mannitol & 1.89 & $0.82-4.37$ & .14 \\
\hline
\end{tabular}

cident, intracerebral hypertensive hemorrhage, subarachnoid hemorrhage, cranioencephalic traumatism, meningoencephalitis, metabolic encephalopathy; however, only a minority of this population had undergone neurosurgery for the resection of an intracerebral tumor. ${ }^{17}$

Few studies have evaluated extubation failure in a specific population of neurosurgery patients, and none of them have evaluated risk factors for extubation failure in nonemergency neurosurgery, as has our study. ${ }^{15,16,18}$ Though our subjects included aneurysm surgery, they were not operated in an emergency situation, and all had the same baseline conditions as the subjects with tumors or arteriovenous malformation.

The variations in extubation failure incidence seen in the literature may also be due to the different definitions
Table 4. Level of Consciousness Regarding the Occurrence of Extubation Failure

\begin{tabular}{lccc}
\hline \hline $\begin{array}{l}\text { Glasgow } \\
\text { Coma } \\
\text { Score }\end{array}$ & $n$ & $\begin{array}{c}\text { Success, } \\
\text { no. }(\%)\end{array}$ & $\begin{array}{c}\text { Failure, } \\
\text { no. }(\%)\end{array}$ \\
\hline $11 \mathrm{~T}$ & 276 & $261(95)$ & $15(5)$ \\
$10 \mathrm{~T}$ & 29 & $22(76)$ & $7(24)$ \\
$9 \mathrm{~T}$ & 11 & $7(64)$ & $4(36)$ \\
$8 \mathrm{~T}$ & 1 & $0(0)$ & $1(100)$ \\
\hline $\mathrm{T}=$ presence of artificial airway and unable to give a verbal response. & \\
\hline
\end{tabular}

adopted in the studies. The time between extubation and reintubation to characterize the failure can range from 24 hours to 72 hours..$^{20,21}$ However, other studies consider failure to be the need for reintubation or tracheostomy at any time following extubation. ${ }^{15}$ In the present study we considered failure to be the need for reintubation within 48 hours following extubation, in keeping with the majority of studies.

The main risk factor for extubation failure was the lower level of consciousness (GCS 8T-10T) at the time of extubation. This finding corroborates the findings of a study by Namen et al, who also observed a higher incidence of 
Table 5. The Incidence of Pulmonary Complications, Mortality, Reoperation, and Hospital Stay in the Postoperative Period, According to the Occurrence of Extubation Failure

\begin{tabular}{lccc}
\hline \hline & $\begin{array}{c}\text { Success } \\
(n=291)\end{array}$ & $\begin{array}{c}\text { Failure } \\
(n=26)\end{array}$ & $P$ \\
\hline $\begin{array}{l}\text { Postoperative pulmonary } \\
\quad \text { complication }\end{array}$ & $43(15)$ & $22(85)$ & $<.001$ \\
$\begin{array}{l}\text { Death } \\
\text { Reoperation }\end{array}$ & $8(3)$ & $10(38)$ & $<.001$ \\
Tracheostomy & $7(2)$ & $10(38)$ & $<.001$ \\
ICU stay, median (IQR) d & $4(1)$ & $7(27)$ & $<.001$ \\
& $2(1-5)$ & $15(10-30)$ & $<.001$
\end{tabular}

Values are number and percent unless otherwise indicated.

extubation failure in neurosurgery patients with a level of consciousness scoring lower than 8 on the GCS. ${ }^{16}$ However, there is no consensus on the consciousness level that the patient could be extubated. Other studies have not found any association between the level of consciousness and extubation failure, ${ }^{15,22}$ which could be due to the fact that the patients with a lower level of consciousness did not exhibit a large amount of secretions, cough deficiency, or swallowing deficiency. However, coughing inefficiency, an abundant amount of secretions, and the incapacity to protect the airways from bronchoaspiration have been described by others as risk factors for extubation fail-

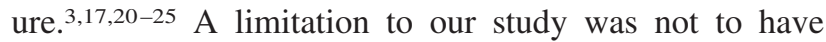
assessed cough or tracheal secretion characteristics at the time of extubation, and therefore we cannot correlate the level of consciousness with these variables and their influence.

The degree of cranial nerve dysfunction and/or bulbar dysfunction could be a likely contributor to the incapacity to protect the airways, but cannot be ascertained by the GCS, although possibly correlating with the GCS in some cases. It would be interesting to evaluate if cranial nerve or bulbar dysfunction is an independent predictor of failure to extubate, separate from the GCS. This is actually quite important in nearly all of the infratentorial cases, and in those supratentorial cases in which preexisting neurologic compromise existed prior to surgery. Unfortunately, both cranial nerve and bulbar dysfunction are difficult to evaluate in intubated patients. Based on the contribution of cranial nerve dysfunction in generating the inability to protect the airways, our initial hypothesis was that there must be an association between extubation failure and infratentorial surgery, but this proved not to be so. Furthermore, we did not find any association between infratentorial surgery and consciousness level. In a previous study by our group, we prospectively studied 92 subjects who required a minimum of 6 hours of MV post craniotomy. All of the subjects had a GCS greater than 8 and were extubated after passing a 30-120 min SBT; 15 (16\%) required reintubation. Reintubation was required in 10 (12\%) of 83 subjects with GCS of $10-11$, and in $5(56 \%)$ of 9 subjects with GCS of 8-9, yielding a sensitivity of 0.33 , a specificity 0.95 , and a positive likelihood ratio of 6.6. As occurred in this present study, we did not control for the adequacy of cough and volume of secretions. ${ }^{14}$ In our previous study we were unable to perform a logistic regression model based on number of subjects, as we did in this study. In previous studies from our group, subjects undergoing elective intracranial surgery showed a higher incidence of pulmonary alterations during the postoperative period. Therefore, they may be more susceptible to postoperative pulmonary complications. ${ }^{26-28}$ We observed in the present study that subjects who experienced extubation failure had a higher incidence of postoperative pulmonary complications $(85 \%)$. Reintubation is a risk factor for the development of pulmonary infection, as it favors bronchoaspiration, which may decrease mucociliary clearance and consequently lead to airway bacterial colonization. ${ }^{29-32}$

Despite the low incidence of extubation failure in the present study $(8.2 \%)$, the subjects who experienced failure spent a longer time in the ICU, which may have had a considerable impact on their hospital costs. Such findings stress the importance of the early identification of risk factors for extubation failure among subjects submitted to intracranial surgery, so that prophylactic measures can be taken. The higher cost of hospitalization for patients with extubation failure should lead us to review the usual practice of early extubation in neurosurgical patients with a low level of consciousness.

A systematic approach to weaning and extubation is more appropriate than the sole physician's judgment in preventing extubation failure rate in patients with neurological disorders, as shown by Navalesi and colleagues. These authors affirm that a systematic weaning protocol could help decrease the extubation failure in neurologic patients. ${ }^{33}$

It was interesting to find that women exhibited a greater likelihood of extubation failure ( 8 times more likely to fail extubation, compared to men). The female sex has also been seen as a predictor of increased mortality and morbidity among patients submitted to myocardial revascularization surgery, for reasons that are as yet unclear. ${ }^{34}$ Légaré et $\mathrm{al}^{35}$ also found that women exhibited a greater risk for prolonged MV. This finding is compatible with a recent review stating that women undergo a longer endotracheal intubation time as well as longer ICU and hospital stay. ${ }^{36}$ In this present study, the higher incidence of extubation failure among women is possibly explained by the greater incidence of women undergoing corrective surgery for aneurysm (40\%, against $22 \%$ among men, $P=.003$ ). In a previous study carried out by our group, ${ }^{28}$ a higher incidence of pulmonary alterations was observed, with a 


\section{Risk Factors for Extubation Failure After Intracranial Surgery}

reduction in vital capacity and tidal volume in patients submitted to non-emergency aneurysm clipping, making them more susceptible to the development of pulmonary complications that could interfere in the weaning process.

In the present study we observed that subjects with a lower level of consciousness were 10 times more likely to incur extubation failure, compared to subjects with normal consciousness level. In this case it is possible that early tracheostomy would be an option for patients with a lower level of consciousness, even when fulfilling other extubation criteria. However, controlled, randomized clinical trials are needed on populations submitted to elective intracranial surgery exhibiting an alteration in level of consciousness, in order to affirm that early tracheostomy would benefit this population.

\section{Conclusions}

We conclude that lower level of consciousness (GCS 8T-10T) and female sex are risk factors for extubation failure in patients submitted to elective intracranial surgery. Therefore, when caring for female neurologic patients with a lower level of consciousness at the moment of extubation, the caring team should be alert to adopt early prophylactic measures.

\section{REFERENCES}

1. Esteban A, Frutos F, Tobin MJ, Alía I, Solsona JF, Valverdú, et al. A comparison of four methods of weaning patients from mechanical ventilation. Spanish Lung Failure Collaborative Group. N Engl J Med 1995;332(6):345-350.

2. Epstein SK. Decision to extubate. Int Care Med 2002;28(5):535-546.

3. MacIntyre NR, Cook DJ, Ely EW Jr, Epstein SK, Fink JB, Heffner $\mathrm{JE}$, et al. Evidence-based guidelines for weaning and discontinuing ventilatory support: a collective task force facilitated by the American College of Chest Physicians; American Association for Respiratory Care; and the American College of Critical Care Medicine. Chest 2001;120(6 Suppl):375S-395S.

4. Epstein SK, Ciubotaru RL. Independent effects of etiology of failure and time to reintubation on outcome for patients failing extubation. Am J Respir Crit Care Med 1998;158(2):489-483.

5. Torres A, Gatell JM, Aznar E, el-Ebiary M, Puig de la Bellacasa J, González J, et al. Re-intubation increases the risk of nosocomial pneumonia in patients needing mechanical ventilation. Am J Respir Crit Care Med 1995;152(1):137-41.

6. King CS, Moores LK, Epstein SK. Should patients be able to follow commands prior to extubation? Respir Care 2010;55(1):56-65.

7. Ingersoll GL, Grippi MA. Preoperative pulmonary status and postoperative extubation outcome of patients undergoing elective cardiac surgery. Heart Lung 1991;20(2):137-143.

8. Leitch EA, Moran JL, Grealy B. Weaning and extubation in the intensive care unit. Clinical or index-driven approach? Intensive Care Med 1996;22(8):752-759.

9. Rady MY, Ryan T. Perioperative predictors of extubation failure and the effect on clinical outcome after cardiac surgery. Crit Care Med 1999;27(2):340-347.
10. Brooks-Brunn JA. Predictors of postoperative pulmonary complications following abdominal surgery. Chest 1997;111(3):564-571.

11. McCulloch TM, Jensen NF, Firod DA, Tsue TT, Weymuller EA Jr. Risk factors for pulmonary complications in the postoperative head and neck surgery patient. Head 1997;19(5):372-377.

12. Ondrula DP, Nelson RL, Prasad ML, Coyle BW, Abcarian H. Multifactorial index of preoperative risk factors in colon resections. Dis Colon Rectum 1992;35(2):117-122.

13. Sogame LCM, Vidotto MC, Jardim JR, Faresin SM. Incidence and risk factors for postoperative pulmonary complications in elective intracranial surgery. J Neurosurg 2008;109(2):222-227.

14. Vidotto MC, Sogame LCM, Calciolari C, Nascimento AO, Jardim JR. The prediction of extubation success of postoperative neurosurgical patients using frequency-tidal volume ratios. Neurocrit Care 2008;9(1):83-89.

15. Coplin WM, Pierson DJ, Cooley KD, Newell DW, Rubenfeld GD. Implications of extubation delay in brain-injured patients meeting standard weaning criteria. Am J Respir Crit Care Med 2000;161(5): 1530-1541.

16. Namen AM, Ely EW, Tatter SB, Case LD, Lucia MA, Smith A, et al. Preditors of successful extubation in neurosurgical patients. Am J Respir Crit Care Med 2001;163(3):658-664.

17. Vallverdú I, Calaf N, Subirana M, Net A, Benito S, Mancebo J. Clinical characteristics, respiratory functional parameters, and outcome of a two-hour $\mathrm{T}$ piece trial in patients weaning from mechanical ventilation. Am J Respir Crit Care Med 1998;158(6):1855-1862.

18. Ko R, Ramos L, Chalela JA. Conventional weaning parameters do not predict extubation failure in neurocritical care patients. Neurocrit Care 2009;10(3):269-273.

19. Pereira EDB, Fernandes ALG, Anção MS, Peres CA, Atallah AN, Farensin SM. Prospective assessment of the risk of postoperative pulmonary complications in patients submitted to upper abdominal surgery. São Paulo Med J 1999;117(4):151-160.

20. Khamiees M, Raju P, DeGirolamo A, Amoateng-Adjepong Y, Manthous CA. Predictors of extubation outcome in patients who have successfully completed a spontaneous breathing trial. Chest 2001; 120(4):1262-1270

21. Frutos-Vivar F, Ferguson ND, Esteban A, Epstein SK, Arabi Y, Apezteguía C. Risk factors for extubation failure in patients following a successful spontaneous breathing trial. Chest 2006;130(6):16641671.

22. Chevron V, Menard JF, Richard JC. Unplanned extubation: risk factors of development in predictive criteria for reintubation. Crit Care Med 1998;26(6):1049-1053.

23. Brochard L, Rauss A, Benito S, Conti G, Mancebo J, Rekik N, et al. Comparison of three methods of gradual withdrawal from ventilatory support during weaning from mechanical ventilation. Am J Respir Crit Care Med 1994;150(4):896-903.

24. Krishnan JA, Moore D, Robeson C, Robeson C, Rand CS. A prospective, controlled trial of a protocol-based strategy to discontinue mechanical ventilation. Am J Respir Crit Care Med 2004;169(6): 673-678.

25. Beuret P, Roux C, Auclair A, Nourdine K, Kaaki M, Carton MJ. Interest of an objective evaluation of cough during weaning from mechanical ventilation. Intensive Care Med 2009;35(6):1090-1093.

26. Franceschini J, Sogame LCM, Gazzotti MR, Jardim JR. Pulmonary Function and Thoraco-abdominal Configuration After Elective Craniotomy. Neurosurg Q 2008;18(1):22-27.

27. Gazzotti MR, Vidotto MC, Sogame LCM, Hayashi LY, Jardim JR. Disminución de la capacidad vital en el período postoperatorio de la craneotomía electiva. Rev Neurol 2008;47(3):124-128.

28. Sogame LCM, Faresin SM, Vidotto M, Jardim JR. Postoperative study of vital capacity and ventilation measurements following elective craniotomy. São Paulo Med J 2008;126(1):11-16. 


\section{Risk Factors for Extubation Failure After Intracranial Surgery}

29. Akça O, Koltka K, Uzel S, Nahit C, Kamil P, Mehmet S, et al. Risk factors for early-onset, ventilator-associated pneumonia in critical care patients. Anesthesiology 2000;93(3):638-645.

30. Wijdicks EFM, Borel CO. Respiratory management in acute neurologic illness. Neurology 1998;50(1):11-20.

31. Hsieh AH, Bishop MJ, Kubilis PS, Newell DW, Pierson DJ. Pneumonia following closed head injury. Am Rev Respir Dis 1992;146(2):290-294.

32. Mcritchie DI, Matthews JG, Fink MP. Pneumonia in patients with multiple trauma. Clin Chest Med 1995;16(1):135-146.

33. Navalesi P, Frigerio P, Moretti MP, Moretti MP, Sommariva M, Vesconi S, et al. Rate of reintubation in mechanically ventilated neurosurgical and neurologic patients: evaluation of a systematic approach to weaning and extubation. Crit Care Med 2008;36(11): 2986-2992.

34. Samuels LE, Kaufman MS, Morris RJ, Promisloff R, Brockman SK. Coronary artery bypass grafting in patients with COPD. Chest 1998; 113(4):878-882.

35. Légaré JF, Hirsch GM, Buth KJ, MacDougall C, Sullivan JA. Preoperative prediction of prolonged mechanical ventilation following coronary artery bypass grafting. Eur J Cardiothorac Surg 2001;20(5): 930-936.

36. Capdeville M, Lee JH, Taylor AL. Effect of gender on fast-track recovery after coronary artery bypass graft surgery. J Cardiothorac Vasc Anesth 2001;15(2):146-151. 